\title{
INFLUÊNCIA DA ENVOLTÓRIA NO DESEMPENHO TERMOENERGÉTICO DE EDIFICAÇÕES INSTITUCIONAIS NO SEMIÁRIDO
}

\section{INFLUENCE OF THE ENVELOPE ON THERMAL AND ENERGY PERFORMANCE OF INSTITUTIONAL BUILDINGS IN SEMI-ARID}

\author{
Paolo Américo de Oliveira ${ }^{1}$ \\ Universidade Federal Rural do Semi-Árido, Mossoró, RN, Brasil, paolo@ufersa.edu.br \\ Diana Gonçalves Lunardi 2 \\ Universidade Federal Rural do Semi-Árido, Mossoró, RN, Brasil, lunardi.diana@ufersa.edu.br
}

\section{Resumo}

A eficiência energética em edificações está relacionada à arquitetura bioclimática, que é a adequação da edificação ao clima local. Este estudo objetivou analisar a influência de determinadas características arquitetônicas e construtivas no consumo de eletricidade de edificações situadas em Mossoró, RN, cujo clima é tropical semiárido. Foram coletados dados relativos às características térmicas e geométricas dos elementos arquitetônicos, como: formato da edificação, disposição e uso dos ambientes, orientação cardeal das fachadas, posicionamento de elementos transparentes e propriedades térmicas dos materiais que compõem os sistemas construtivos. Para análise do desempenho termoenergético de parâmetros como transmitância e absortância térmica de paredes externas e da cobertura, percentual de aberturas nas fachadas, ângulos verticais de sombreamento de elementos translúcidos e orientação cardeal das edificações, utilizou-se o programa EnergyPlus, que simula o consumo de eletricidade predial ao longo do ano, baseado em modelos similares às edificações deste estudo. Nestas edificações, em função das variáveis arquitetônicas testadas, o condicionamento artificial de ar foi o principal responsável pela variação de consumo anual de eletricidade, enquanto que o consumo de sistemas de iluminação artificial e de equipamentos permaneceu constante em todos os cenários simulados. Adicionalmente, os revestimentos claros e refletivos das edificações, o baixo percentual de áreas envidraçadas nas fachadas e a existência de elementos de sombreamento contribuíram para minimizar os efeitos da radiação solar no aquecimento das edificações. A partir deste diagnóstico, são propostas recomendações projetuais para envoltória de edificações termicamente eficientes, inseridas no clima tropical semiárido e que tenham a necessidade de condicionamento artificial de ar.

Palavras-chave: Arquitetura bioclimática. Eficiência energética. Simulação computacional.

\begin{abstract}
Energy efficiency in buildings is related to the bioclimatic architecture, which is the adequacy of the building to the local climate. This study aimed to analyze the influence of specific architectural and construction characteristics on the electricity consumption in buildings located at Mossoró, RN, whose climate is tropical semi-arid. We recorded data of thermal and geometric characteristics of the architectural elements, such as building shape, layout, and use of spaces, the cardinal orientation of facades, positioning of translucent elements and thermal properties of construction systems materials. For the thermal and energy performance analysis of parameters such as thermal transmittance and absorptance of external walls and roofs, window-to-wall ratio, vertical shading angles of translucent openings and buildings cardinal orientation, the EnergyPlus program was used to simulate electricity consumption throughout the year, based on models similar to the target buildings of this study. In these buildings, due to the architectural variables tested, artificial air conditioning was the main factor responsible for the variation of annual electricity consumption, while the consumption of artificial lighting and equipment remained constant in all simulated scenarios. Besides, the bright and reflective buildings coatings, the low window-to-wall ratio and the existence of shading elements contributed to minimizing the effects of solar radiation on the heating of the building. For this diagnosis, project recommendations are proposed for a thermally efficient building's envelope, inserted in the semi-arid tropical climate and requiring artificial air conditioning.
\end{abstract}

Keywords: Bioclimatic architecture. Energy efficiency. Computer simulation.

\section{How to cite this article:}

OLIVEIRA, Paolo Américo de; LUNARDI, Diana Gonçalves. Influência da envoltória no desempenho termoenergético de edificações institucionais no semiárido. PARC Pesquisa em Arquitetura e Construção, Campinas, SP, v. 9, n. 4, p. 276-289, dez. 2018. ISSN 1980-6809. Disponível em: <https://periodicos.sbu.unicamp.br/ojs/index.php/parc/article/view/8651048>. Acesso em: 21 nov. 2018. DOl:https://doi.org/10.20396/parc.v9i4.8651048. 


\section{Introdução}

A energia elétrica consumida ao longo da vida útil da edificação representa um dos maiores custos operacionais de um empreendimento e a ineficiência no consumo colabora para a necessidade de ampliação dos investimentos necessários para geração e distribuição da eletricidade. Outro efeito econômico, resultante da ampliação da demanda por eletricidade devido ao consumo ineficiente, é que este processo provoca o aumento do preço da eletricidade, por criar pressões inflacionárias quanto à oferta por mais energia elétrica (KATS, 2014). A depender do tipo de fonte, o consumo de eletricidade também é potencialmente responsável por uma parcela relevante das emissões de gases que potencializam o efeito estufa (ARENT et al., 2014; JI et al., 2016). Nesse aspecto, instituíram-se os sistemas de certificação ambiental e energética. Para a avaliação do desempenho de edificações, essas certificações são aplicáveis em diversas tipologias arquitetônicas como residências, condomínios, loteamentos, escolas, unidades comerciais e indústrias. Entre os principais objetivos dos sistemas de certificação ambiental de edificações está a fixação de parâmetros que definem uma edificação como sustentável (GRÜNBERG; MEDEIROS; TAVARES, 2014; PÉREZ-LOMBARD et al., 2009; REY; VELASCO; VARELA, 2007; STANKEVICIUS; KARBAUSKAITE; MONSTVILAS, 2007).

Como já ocorre em alguns países da União Europeia e nos Estados Unidos, na Austrália e no Japão, foi criado também no Brasil a Etiqueta Nacional de Conservação de Energia de Edificações (ENCE) com o objetivo de difundir boas práticas que incentivem a redução do desperdício energético e orientar o planejamento das novas edificações quanto ao uso racional de eletricidade (CARLO; LAMBERTS, 2010a; GRÜNBERG; MEDEIROS; TAVARES, 2014). Os parâmetros técnicos considerados na aplicação da ENCE de edificações comerciais e institucionais foram estabelecidos por meio do Regulamento Técnico da Qualidade do Nível de Eficiência Energética de Edifícios Comerciais, de Serviços e Públicos (RTQ-C) (INMETRO, 2010). Estudos anteriores identificaram relações diretas entre as características prediais e a influência destas propriedades nos ganhos e perdas térmicas, e consequentemente no consumo de energia elétrica de edificações, de acordo com o contexto climático (CARLO; LAMBERTS, 2008; MARTINEZ et al., 2009). A arquitetura bioclimática é um tipo de arquitetura que objetiva o projeto de edificações de modo a adaptá-los eficazmente ao seu contexto climático. Por exemplo, a utilização de sistemas construtivos de maior densidade, com grande inércia térmica, para adequação da temperatura do ar no interior das edificações em regiões de clima semiárido, é uma estratégia bioclimática que contribui para a sua eficiência energética (LAMBERTS; DUTRA; PEREIRA, 2014; SZOKOLAY, 2008).

Nas edificações de uso comercial ou de serviços, o consumo de energia elétrica com sistemas de condicionamento artificial é significativo, pois, em alguns casos, este uso final pode representar mais da metade do seu consumo de energia elétrica (KATS, 2014; LAMBERTS et al., 2014). Isso se deve à concepção de uma arquitetura que remete a formas prismáticas com fachadas envidraçadas, muito comuns em edificações corporativas localizadas em regiões de clima frio, mas que em climas quentes podem gerar uma série de problemas relacionados ao excessivo consumo energético, causados pela exposição direta dos elementos translúcidos à radiação solar. A radiação solar que atravessa os elementos translúcidos é absorvida pelos componentes construtivos no interior da construção, o que provoca o acúmulo de energia térmica no interior da edificação. Nesse contexto, é recomendável que se incentive o uso de elementos que minimizem o ganho térmico gerado pelas fachadas envidraçadas expostas à radiação, tais como brise-soleil, marquises e varandas (MARTINEZ et al., 2009; SZOKOLAY, 2008). As características da envoltória são fatores determinantes para adequação do desempenho termoenergético na arquitetura (OLIVEIRA et al., 2016). Portanto, a eficiência de uma envoltória se baseia no quanto ela protege a edificação da ação provocada pelas trocas térmicas entre o exterior e o interior (CARLO; LAMBERTS, 2010a; 2010b).

O clima quente e seco é classificado como BSh, de acordo com o sistema de Köppen-Geiger (ALVARES et al., 2013). Em climas quentes e secos, as condições ambientais normalmente ultrapassam os patamares aceitáveis para atendimento das exigências humanas de conforto térmico (BALSLEV; POTCHTER; MATZARAKIS, 2015). As estratégias de condicionamento passivo em climas quentes e secos, como a utilização de elementos construtivos de grande inércia térmica, combinados ao uso de ventilação natural noturna, são bastante comuns para promover a remoção do calor acumulado pela construção sem a utilização de equipamentos de condicionamento artificial de ar (CORGNATI; KINDINIS, 2007).

Este estudo objetivou analisar a influência de determinadas características arquitetônicas e construtivas no consumo de eletricidade de edificações institucionais situadas em Mossoró, RN, cujo clima é tropical semiárido. Objetivou-se analisar a influência de determinadas características arquitetônicas e construtivas no consumo de eletricidade de edificações situadas em Mossoró, RN, cujo clima é tropical semiárido. Foram considerados, neste estudo, formato da edificação, posicionamento de elementos transparentes como janelas e portas e de elementos de sombreamento em relação à orientação 
cardeal das fachadas, disposição e tipo de uso dos ambientes e propriedades térmicas dos materiais especificados.

\section{Material e métodos}

Para atendimento aos objetivos, a coleta de dados foi organizada em duas etapas: levantamento das características das edificações a serem estudadas e determinação de parâmetros a serem testados por meio de modelos comparativos e inserção das características das edificações estudadas e dos modelos propostos no programa EnergyPlus (DOE, 2015) para, por meio da simulação computacional, obter-se os dados referentes ao consumo anual de energia elétrica nessas edificações. Por meio da análise comparativa dos dados referentes aos consumos de eletricidade simulados, demonstram-se quais aspectos arquitetônicos são determinantes para o consumo de energia elétrica no contexto climático estudado.

\section{Caracterização das edificações alvo}

Para a amostragem deste estudo, foram selecionadas três edificações localizadas no Campus da Universidade Federal Rural do Semi-Árido (UFERSA) em Mossoró (Figura 1), ocupando uma área que se estende entre as zonas urbana e rural do município de Mossoró, RN. Neste campus, está situada a estação meteorológica que forneceu os dados formatados e disponibilizados por Roriz (2012) para utilização no programa EnergyPlus. As três edificações analisadas foram: Central de Aulas 3 (CA3), Central de Aulas 6 (CA6) e Laboratório de Química, Física e Matemática (QFM) (Figuras 2, 3 e 4). A Central de Aulas 3 é utilizada para realização de aulas teóricas e caracterizase por possuir um único pavimento com grande extensão horizontal. A Central de Aulas 6 também é usada para aulas teóricas e possui dois pavimentos com área de projeção horizontal menor, sendo, portanto, uma edificação volumetricamente mais compacta. $\mathrm{O}$ Laboratório de Química, Física e Matemática possui um formato muito semelhante à Central de Aulas 6, com dois pavimentos e área horizontal equivalente. Porém, esta edificação é utilizada de modo distinto dos demais objetos desse estudo, por se tratar de laboratórios com equipamentos específicos e número de usuários menor do que aqueles onde são ministradas aulas teóricas (Central de Aulas). As três edificações possuem estrutura em concreto armado, lajes compostas de tavelas em cerâmica e vigotas em concreto pré-moldado. Estas edificações possuem paredes externas e internas de alvenaria, com blocos cerâmicos de 8 furos, rebocadas com argamassa em ambos os lados. Os fechamentos translúcidos são compostos por esquadrias de alumínio cinza com vidros transparentes de $3 \mathrm{~mm}$ de espessura. Na Tabela 1, são apresentadas as principais características e variáveis usadas nas simulações com o programa EnergyPlus para as três edificações estudadas.

Figura 1 - Localização das três edificações estudadas no Campus da Universidade Federal Rural do Semi-Árido - UFERSA em Mossoró, Rio Grande do Norte, Brasil

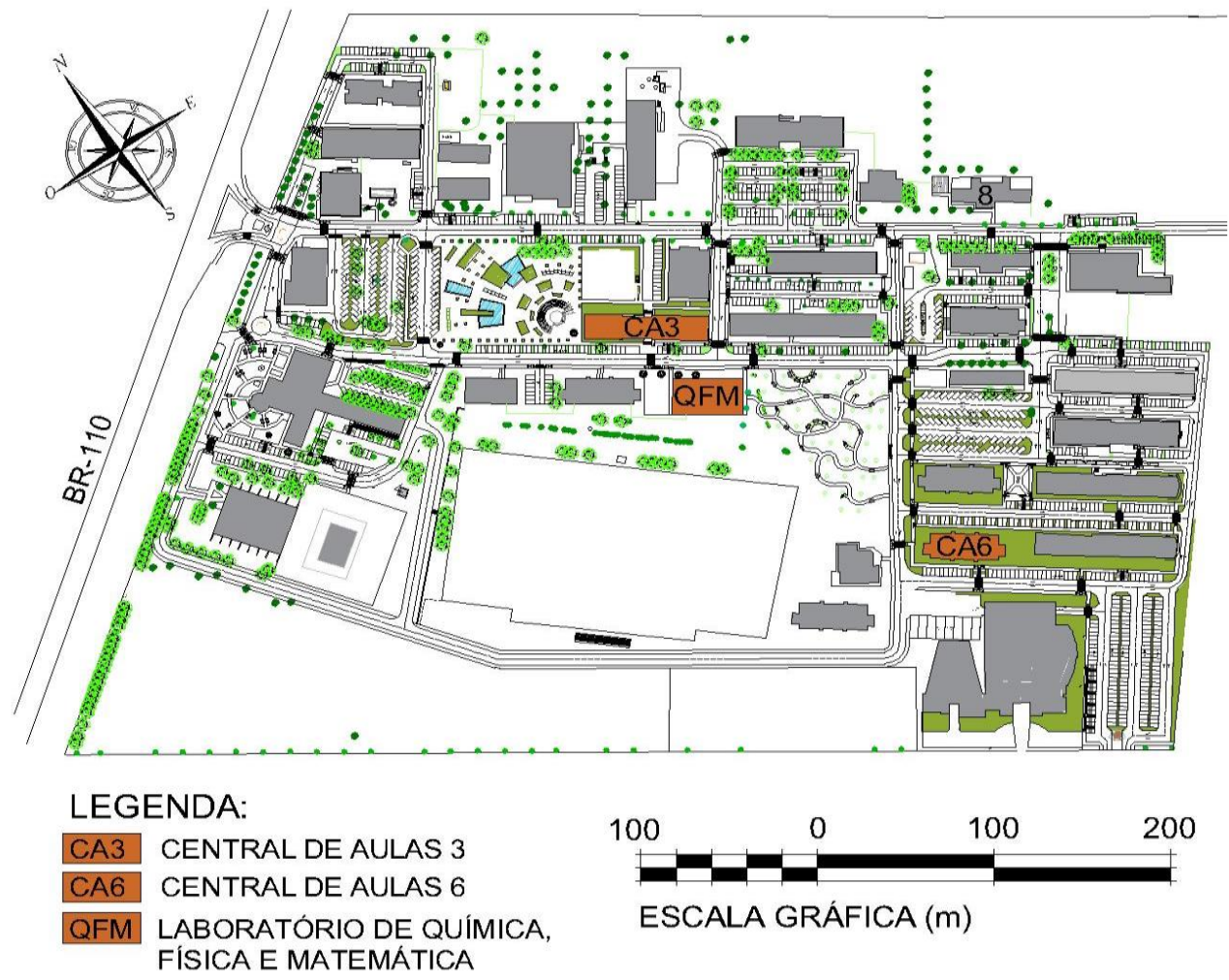

Fonte: Os autores. 
Figura 2 - Fotografia, representação tridimensional dos modelos analisados no EnergyPlus e planta baixa: Central de Aulas 3
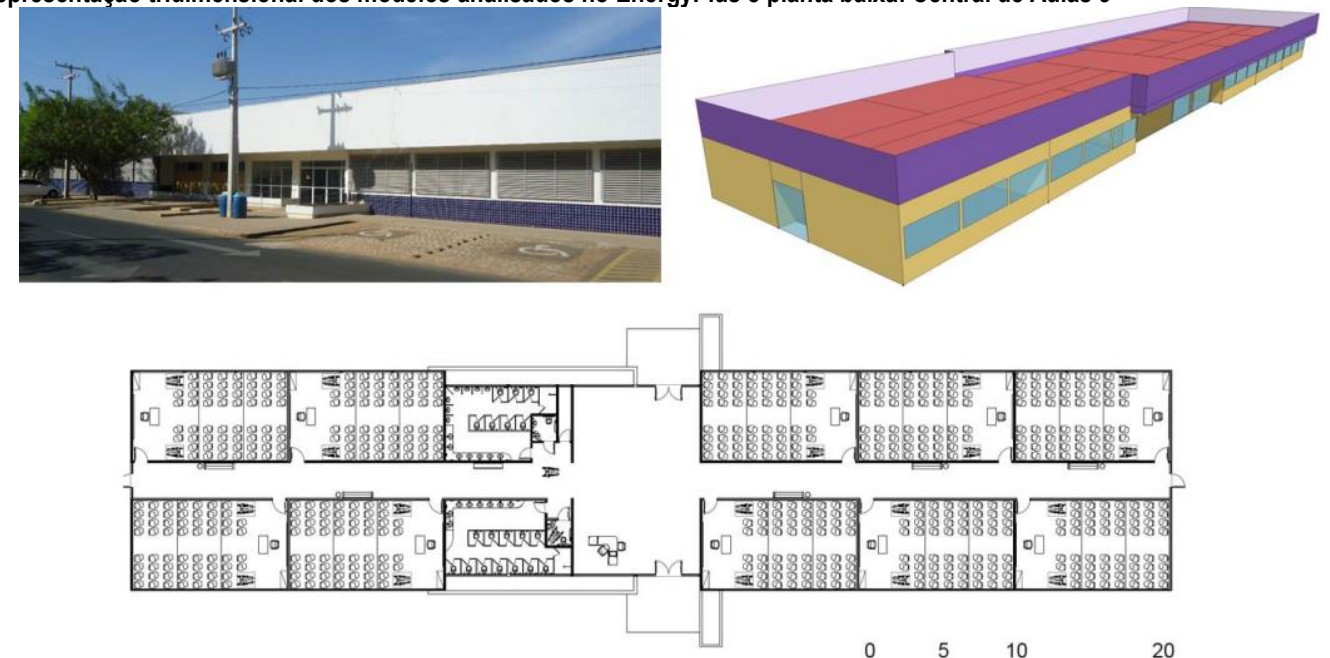

Fonte: Os autores.

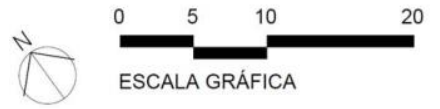

Figura 3 - Fotografia, representação tridimensional dos modelos analisados no EnergyPlus e plantas baixas: Central de Aulas 6
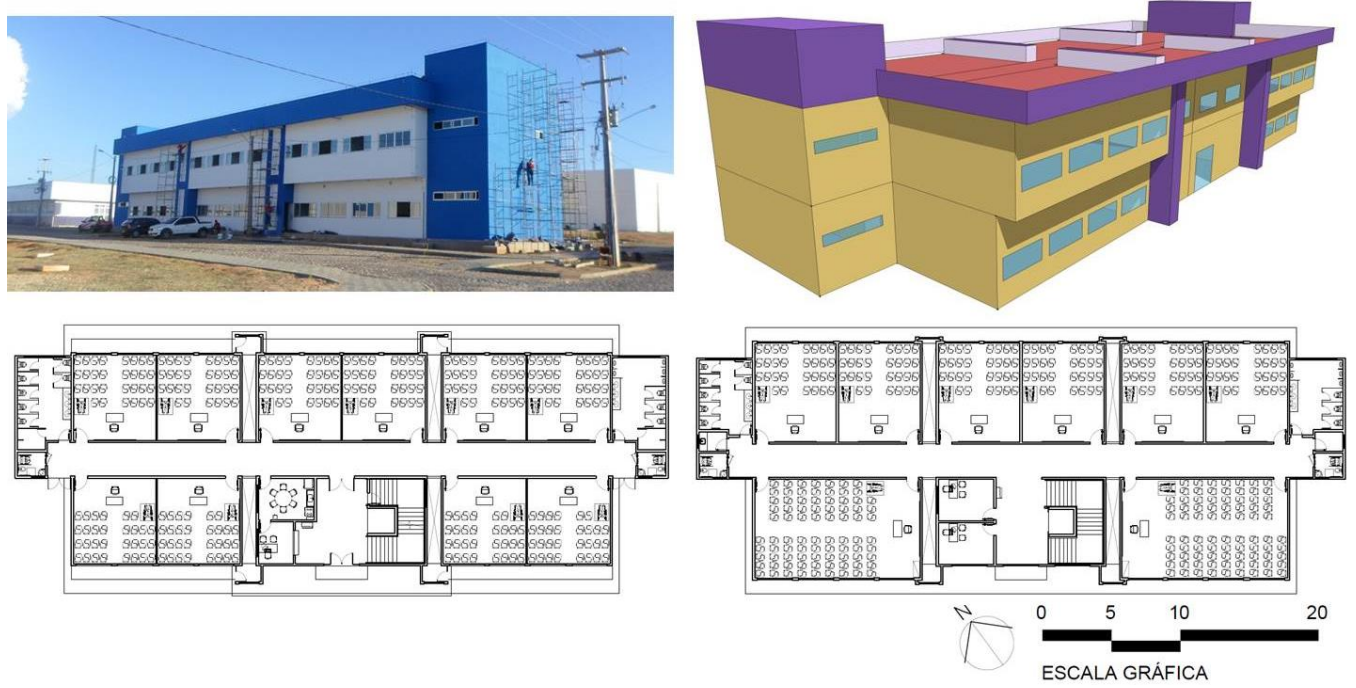

Fonte: Os autores.

Figura 4 - Fotografia, representação tridimensional dos modelos analisados no EnergyPlus e plantas baixas: Lab. de Química, Física e Matemática
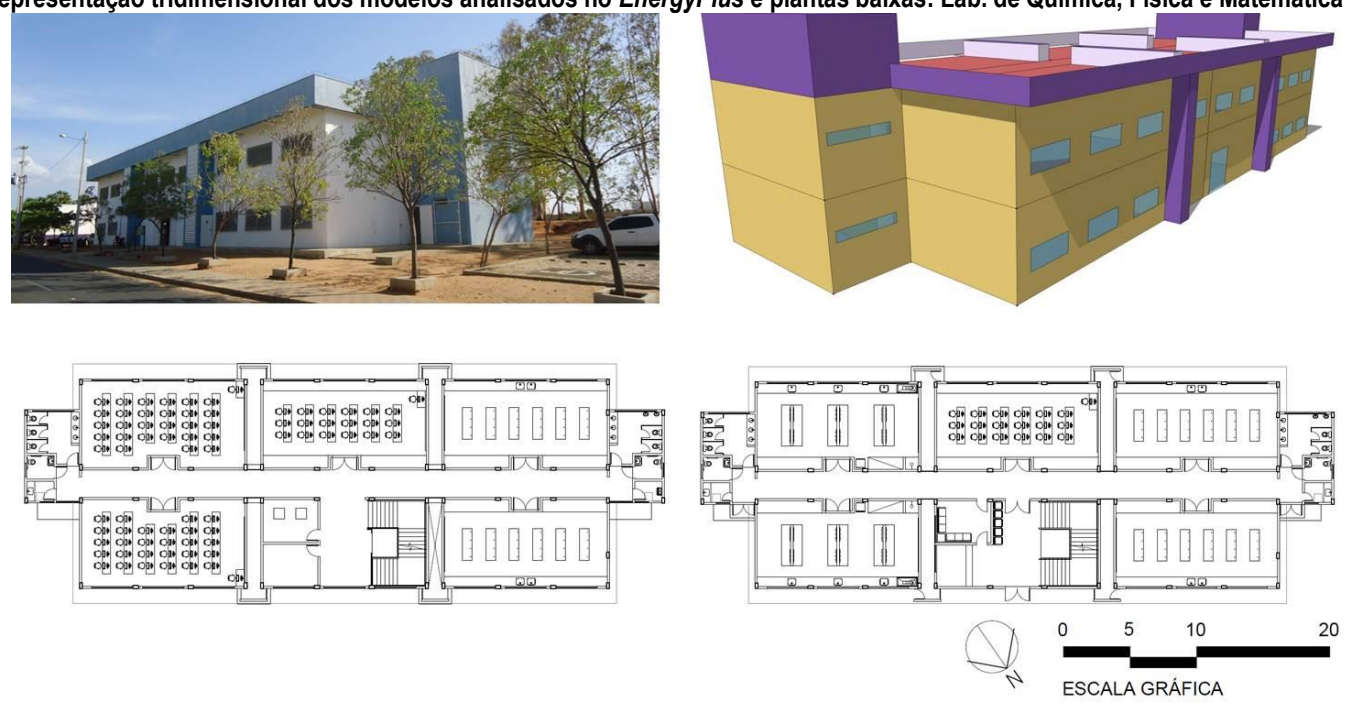

Fonte: Os autores. 
Tabela 1 - Características das três edificações investigadas na Universidade Federal Rural do Semi-Árido - UFERSA, Mossoró, Rio Grande do Norte, Brasil

\begin{tabular}{|c|c|c|c|}
\hline Edificações analisadas & Central de Aulas $3^{*}$ & Central de Aulas $6^{*}$ & $\begin{array}{l}\text { Laboratório de Química, Física } \\
\text { e Matemática* }\end{array}$ \\
\hline $\begin{array}{l}\text { Transmitância térmica de paredes externas } \\
\text { e internas }\end{array}$ & $\begin{array}{c}2,48 \mathrm{~W} / \mathrm{m}^{2} . \mathrm{K} \\
\text { (Alvenaria com blocos cerâmicos } \\
\text { de } 8 \text { furos, rebocada com } \\
\text { argamassa em ambos os lados) }\end{array}$ & $\begin{array}{c}2,48 \mathrm{~W} / \mathrm{m}^{2} . \mathrm{K} \\
\text { (Alvenaria com blocos cerâmicos } \\
\text { de } 8 \text { furos, rebocada com } \\
\text { argamassa em ambos os lados) }\end{array}$ & $\begin{array}{l}2,48 \mathrm{~W} / \mathrm{m}^{2} . \mathrm{K} \\
\text { (Alvenaria com blocos cerâmicos } \\
\text { de } 8 \text { furos, rebocada com } \\
\text { argamassa em ambos os lados) }\end{array}$ \\
\hline $\begin{array}{l}\text { Transmitância térmica de elementos de } \\
\text { cobertura** }\end{array}$ & $\begin{array}{c}1,04 \mathrm{~W} / \mathrm{m}^{2} . \mathrm{K} \\
\text { (telha de fibrocimento sobre laje } \\
\text { de tavelas cerâmicas e vigotas } \\
\text { em concreto e forro de PVC) }\end{array}$ & $\begin{array}{c}0,69 \mathrm{~W} / \mathrm{m}^{2} . \mathrm{K} \\
\text { (telha de fibrocimento sobre laje } \\
\text { de tavelas cerâmicas e vigotas em } \\
\text { concreto e forro de lã de vidro) }\end{array}$ & $\begin{array}{c}0,69 \mathrm{~W} / \mathrm{m}^{2} . \mathrm{K} \\
\text { (telha de fibrocimento sobre laje } \\
\text { de tavelas cerâmicas e vigotas em } \\
\text { concreto e forro de lã de vidro) }\end{array}$ \\
\hline $\begin{array}{c}\text { Absortância térmica de paredes } \\
\text { externas }^{* * *}\end{array}$ & $\begin{array}{c}\text { Entre } 15,8 \% \text { (cor branca) e } \\
73,3 \% \text { (cor azul) }\end{array}$ & $\begin{array}{c}\text { Entre } 15,8 \% \text { (cor branca) e } \\
73,3 \% \text { (cor azul) }\end{array}$ & $\begin{array}{c}\text { Entre } 15,8 \% \text { (cor branca) e } \\
73,3 \% \text { (cor azul) }\end{array}$ \\
\hline $\begin{array}{c}\text { Absortância térmica de elementos de } \\
\text { cobertura*** }^{*}\end{array}$ & $59,3 \%$ (cor cinza) & $59,3 \%$ (cor cinza) & $59,3 \%$ (cor cinza) \\
\hline $\begin{array}{l}\text { Percentual de aberturas nas fachadas } \\
\text { (PAF) }\end{array}$ & $31 \%$ & $18 \%$ & $14 \%$ \\
\hline \multirow[t]{2}{*}{$\begin{array}{l}\text { Sombreamento de elementos translúcidos } \\
\text { nas fachadas }\end{array}$} & $23^{\circ}$ & $22^{\circ}$ & $12^{\circ}$ \\
\hline & 0,87 & 0,87 & 0,87 \\
\hline
\end{tabular}

Fator solar dos elementos translúcidos ${ }^{\star * *} \quad$ (vidro simples transparente, $3 \mathrm{~mm}$

(vidro simples transparente, $3 \mathrm{~mm} \quad$ (vidro simples transparente, $3 \mathrm{~mm}$

\begin{tabular}{cccc} 
& de espessura) & de espessura) & de espessura) \\
\hline Azimute da fachada principal & $36^{\circ}$ & $217^{\circ}$ & $35^{\circ}$ \\
\hline Área total construída & $1027,55 \mathrm{~m}^{2}$ & $1323,24 \mathrm{~m}^{2}$ & $1262,24 \mathrm{~m}^{2}$ \\
\hline Área de cobertura & $1027,55 \mathrm{~m}^{2}$ & $692,12 \mathrm{~m}^{2}$ & $631,12 \mathrm{~m}^{2}$ \\
\hline Área condicionada & $670,95 \mathrm{~m}^{2}$ & $893,00 \mathrm{~m}^{2}$ & $832,00 \mathrm{~m}^{2}$ \\
\hline Área não-condicionada & $356,90 \mathrm{~m}^{2}$ & $430,24 \mathrm{~m}^{2}$ & $430,24 \mathrm{~m}^{2}$ \\
\hline Número de pavimentos & 1 & 2 & 2 \\
\hline Fator de forma & 0,32 & 0,32 \\
\hline Índice de compacidade & 0,46 & $68,56 \%$ & $67,88 \%$ \\
\hline
\end{tabular}

12 salas de aula $\left(39,04 \mathrm{~m}^{2}\right)$,

4 salas de aula $\left(45,16 \mathrm{~m}^{2}\right)$,

2 salas de aula $\left(90,28 \mathrm{~m}^{2}\right)$

4 salas técnicas $\left(12,30 \mathrm{~m}^{2}\right)$, circulações $\left(290,24 \mathrm{~m}^{2}\right) \mathrm{e}$

4 banheiros $\left(140,00 \mathrm{~m}^{2}\right)$ circulações $\left(264,91 \mathrm{~m}^{2}\right) \mathrm{e}$ 4 banheiros $\left(91,70 \mathrm{~m}^{2}\right)$

$22,80 \mathrm{~W} / \mathrm{m}^{2}$ (salas de aula), 5,45 $\mathrm{W} / \mathrm{m}^{2}$ (circulações) e $6,43 \mathrm{~W} / \mathrm{m}^{2}$ (banheiros)

$23,57 \mathrm{~W} / \mathrm{m}^{2}$ (salas de aula),

$3,72 \mathrm{~W} / \mathrm{m}^{2}$ (circulações) e

$5,14 \mathrm{~W} / \mathrm{m}^{2}$ (banheiros)

$5,96 \mathrm{~W} / \mathrm{m}^{2}$ (salas de aula) e $0,18 \quad 5,12 \mathrm{~W} / \mathrm{m}^{2}$ (salas de aula) e $\mathrm{W} / \mathrm{m}^{2}$ (circulações) $0,13 \mathrm{~W} / \mathrm{m}^{2}$ (circulações)

10 laboratórios $\left(78,08 \mathrm{~m}^{2}\right)$ 4 salas técnicas $\left(12,30 \mathrm{~m}^{2}\right)$ circulações $\left(290,24 \mathrm{~m}^{2}\right)$ e 4 banheiros $\left(140,00 \mathrm{~m}^{2}\right)$

$27,25 \mathrm{~W} / \mathrm{m}^{2}$ (laboratórios), 3,72

$\mathrm{W} / \mathrm{m}^{2}$ (circulações) e $5,14 \mathrm{~W} / \mathrm{m}^{2}$ (banheiros)

$51,22 \mathrm{~W} / \mathrm{m}^{2}$ (laboratórios) e 0,13 $\mathrm{W} / \mathrm{m}^{2}$ (circulações)

\begin{tabular}{ccc} 
Densidade instalada de equipamentos & $\begin{array}{c}5,96 \mathrm{~W} / \mathrm{m}^{2} \text { (salas de aula) e } 0,18 \\
\mathrm{~W} / \mathrm{m}^{2} \text { (circulações) }\end{array}$ & $\begin{array}{c}5,12 \mathrm{~W} / \mathrm{m}^{2} \text { (salas de aula) e } \\
0,13 \mathrm{~W} / \mathrm{m}^{2} \text { (circulações) }\end{array}$ \\
\hline Sistema de condicionamento artificial de ar & Split & Split \\
\hline Coeficiente de Performance (COP) & $3,0 \mathrm{~W} / \mathrm{W}$ & $3,0 \mathrm{~W} / \mathrm{W}$ \\
\hline Temperatura de setpoint para refrigeração & $24^{\circ} \mathrm{C}$ & $24^{\circ} \mathrm{C}$ \\
Número de ocupantes por ambiente & $0,94 \mathrm{pessoa} / \mathrm{m}^{2}$ (sala de aula), & $0,94 \mathrm{pessoa} / \mathrm{m}^{2}$ (sala de aula), \\
& 0,11 pessoal $/ \mathrm{m}^{2}$ (circulações) e & $0,08 \mathrm{pessoa} / \mathrm{m}^{2}$ (sala técnica), \\
& 0,13 pessoa $/ \mathrm{m}^{2}$ (banheiros) & $0,11 \mathrm{pessoa} / \mathrm{m}^{2}$ (circulações) e \\
& $0,13 \mathrm{pessoa} / \mathrm{m}^{2}$ (banheiros)
\end{tabular}

*Informações obtidas dos projetos arquitetônicos e de instalações prediais, memoriais descritivos, e visitas in loco.

**Transmitância térmica calculada a partir do método descrito na NBR 15220 (ABNT, 2005).

${ }^{* * *}$ Considerou-se os valores contidos no Anexo V do RTQ-C (INMETRO, 2013).

****Valores médios dos ângulos verticais de sombreamento (AVS), calculados conforme a definição e o método descrito pelo INMETRO (2010).

*****Fator de forma calculado conforme a definição e o método descrito pelo INMETRO (2010).

******|ndice de compacidade calculado conforme a definição e o método descrito por Mascaró (2004).

Fonte: Os autores.

\section{Caracterização do contexto climático}

No estado do Rio Grande do Norte, há uma faixa do litoral de aproximadamente $150 \mathrm{~km}$ cuja pluviosidade anual é inferior a $650 \mathrm{~mm}$, sendo esta área a região costeira mais seca e quente de todo o litoral brasileiro. É nessa região próxima à costa que está situado o município de Mossoró, onde é comum a ocorrência de temperaturas atmosféricas médias anuais acima de $26,5^{\circ} \mathrm{C}$ (ALVARES et al., 2013).
Os níveis de irradiação solar apresentam médias mensais entre 900 e $1.100 \mathrm{Wh} / \mathrm{m}^{2}$ e os ventos predominantes no município normalmente atingem velocidades de até $6 \mathrm{~m} / \mathrm{s}$, originando-se da direção leste ou nordeste. A Figura 5 apresenta, em uma carta psicrométrica, valores de umidade e temperatura de bulbo seco, para o município de Mossoró, ao longo de um ano típico em formato EPW, elaborado a partir dos dados registrados pelo Instituto 
Nacional de Meteorologia - INMET entre os anos de 2001 e 2010 (RORIZ, 2012).

Figura 5 - Carta Psicrométrica para o município de Mossoró, Rio Grande do Norte, Brasil

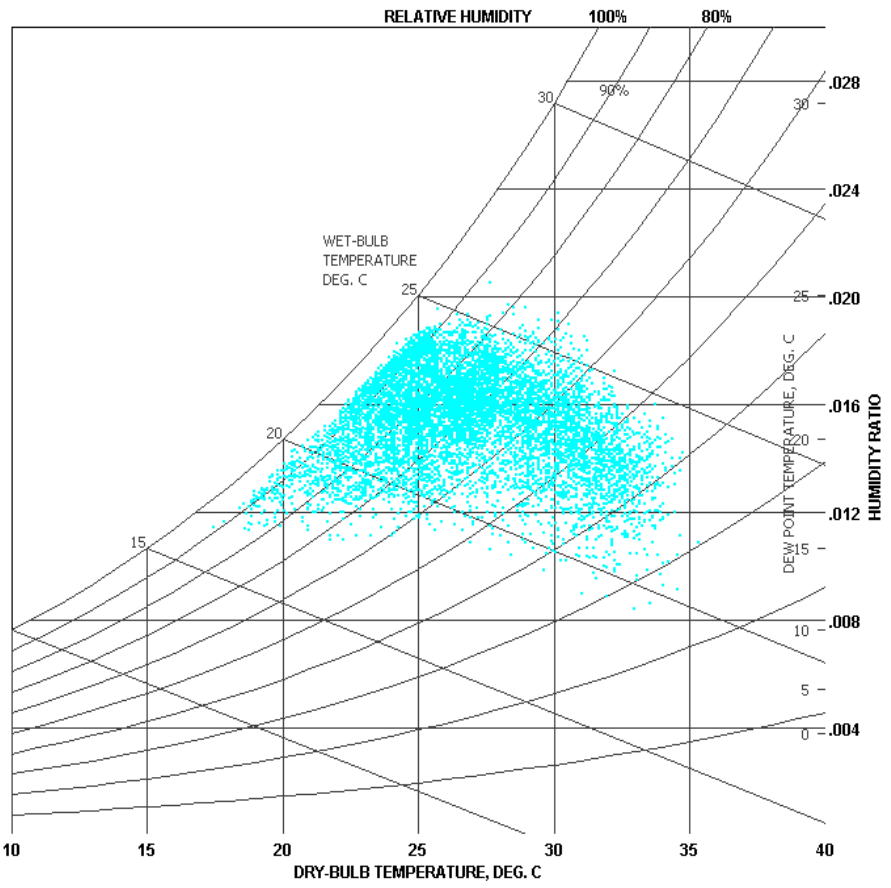

Fonte: Roriz (2012), adaptado no software Climate Consultant 6.0 .

\section{Simulação Computacional}

A simulação computacional de desempenho termoenergético foi utilizada para estimar o consumo de energia de edificações a partir do cômputo da quantidade de calor que a edificação recebe ou perde ao longo do tempo. Esta estimativa foi obtida a partir das interações térmicas entre a edificação e o meio externo, que são determinadas pela atuação dos condicionantes climáticos, por caraterísticas da envoltória e dos elementos internos da edificação, das instalações prediais e pela dinâmica de funcionamento da edificação (AHMAD; SZOKOLAY,
2017; FUMO; MAGO; LUCK, 2010, NEVES; MACHADO; CAVALCANTE, 2016).

Para modelagem virtual, configurou-se 126 modelos computacionais com as características relativas ao que se pretendeu analisar. Por meio dessas modelagens virtuais, obteve-se as estimativas referentes ao consumo anual de energia elétrica por edificação e ao comportamento térmico da edificação, de acordo com as características construtivas simuladas (Tabela 2). Os modelos e parâmetros testados foram agrupados em: modelos análogos às edificações estudadas (caso base); modelos configurados conforme os parâmetros estabelecidos pelo INMETRO (2010) para os níveis de qualificação A, B, C e D (modelos referência) e modelos com modificações específicas dos aspectos construtivos considerados para cada um dos testes de hipóteses (modelos para teste de variáveis). Estes últimos foram agrupados conforme a transmitância térmica de paredes externas e a transmitância térmica de elementos de cobertura, calculados conforme a NBR 15220-2 (ABNT, 2005); absortância térmica de paredes externas e absortância térmica de elementos de cobertura, conforme valores indicados no Anexo V do RTQ-C (INMETRO, 2013); percentual de aberturas nas fachadas; sombreamento de elementos translúcidos nas fachadas e orientação cardeal das edificações.

No Quadro 1, são apresentadas as rotinas de uso das edificações. Durante o período de férias, no qual a população que ocupa os espaços é mínima, adotou-se que o número de usuários e o intervalo de ocupação representa apenas 1/20 (um vigésimo) do que é habitual durante o período letivo. Essa aproximação adotada objetivou estimar o uso dos espaços com atividades eventuais, como a reposição de aulas e o uso contínuo de equipamentos em experimentos de longa duração, e que, portanto, são eventos que apresentam delimitação temporal imprecisa.

Tabela 2 - Parâmetros utilizados nas simulações das edificações estudadas na Universidade Federal Rural do Semi-Árido - UFERSA, Mossoró, Rio Grande do Norte, Brasil, no programa EnergyPlus

\begin{tabular}{|c|c|c|}
\hline & Casos Base - Edificações estudadas & $\begin{array}{c}\text { Central de Aulas 3, Central de Aulas } 6 \text { e Laboratório de } \\
\text { Química, Física e Matemática }\end{array}$ \\
\hline & Modelos de referência* & Niveis A, B, C e D \\
\hline \multirow{7}{*}{$\begin{array}{l}\text { Modelos para teste de } \\
\text { variáveis }{ }^{* *}\end{array}$} & Transmitância térmica de paredes externas $\left(\mathrm{W} / \mathrm{m}^{2} . \mathrm{K}\right)$ & 0,$38 ; 2,02 ; 2,30 ; 3,13$ e 5,04 \\
\hline & Transmitância térmica de elementos de cobertura $\left(\mathrm{W} / \mathrm{m}^{2} . \mathrm{K}\right)$ & 0,$41 ; 1,04 ; 1,06 ; 3,08$ e 4,60 \\
\hline & Absortância térmica de paredes externas (\%) & $10,30,50,70$ e 90 \\
\hline & Absortância térmica de elementos de cobertura (\%) & $10,30,50,70$ e 90 \\
\hline & Percentual de superfícies translúcidas nas fachadas (\%) & $10,30,50$ e 70 \\
\hline & Sombreamento de elementos translúcidos nas fachadas ${ }^{\star * *}$ & $0^{\circ}, 15^{\circ}, 30^{\circ}, 45^{\circ}$ e $60^{\circ}$ \\
\hline & Orientação cardeal das edificações ${ }^{\star \star * *}$ & $\mathrm{~N}, \mathrm{NE}, \mathrm{E}, \mathrm{SE}, \mathrm{S}, \mathrm{SW}, \mathrm{W}$ e NW \\
\hline
\end{tabular}

*Todas as características dimensionais e de implantação são idênticas às edificações analisadas (Casos Base), excluindo-se os elementos de sombreamento e variando-se as propriedades térmicas dos componentes de envoltória e o percentual de abertura nas fachadas conforme indicado na metodologia do INMETRO (2010).

${ }^{\star *}$ Todas as características dimensionais e de implantação são idênticas às edificações analisadas (Casos Base), variando-se apenas a propriedade arquitetônica/construtiva testada no modelo simulado.

***Valores dos ângulos verticais de sombreamento (AVS), calculados conforme a definição e o método descrito pelo INMETRO (2010).

****Utilizou-se como referência o ângulo azimute da fachada principal (ver Figuras 1 a 4 e Tabela 1).

Fonte: Os autores. 


\begin{tabular}{|c|c|c|c|}
\hline \multicolumn{2}{|c|}{ Período } & $\begin{array}{c}\text { Dias úteis } \\
\text { (de segunda-feira a }\end{array}$ & $\begin{array}{c}\text { Sábados } \\
\mathrm{e}\end{array}$ \\
\hline Férias & $\begin{array}{l}\text { Entre } 16 \text { de } \\
\text { dezembro e } \\
15 \text { de } \\
\text { fevereiro }\end{array}$ & $\begin{array}{c}\text { Ocupação mínima entre } \\
\text { 07:00h e 11:30h e 13:00h } \\
\text { e 17:30h }\end{array}$ & \multirow{4}{*}{$\begin{array}{c}\text { Desocupa } \\
\text { do }\end{array}$} \\
\hline $\begin{array}{l}1^{0} \text { semestre } \\
\text { letivo }\end{array}$ & $\begin{array}{l}\text { Entre } 16 \text { de } \\
\text { fevereiro e } 30 \\
\text { de junho }\end{array}$ & $\begin{array}{l}\text { Ocupado entre 07:00h e } \\
\text { 11:30h, 13:00h e 17:30h } \\
\text { e 18:30h e 22:00h }\end{array}$ & \\
\hline Férias & $\begin{array}{l}\text { Entre } 1^{\circ} \text { e } 31 \\
\text { de julho }\end{array}$ & $\begin{array}{c}\text { Ocupação mínima entre } \\
\text { 07:00h e 11:30h e } \\
\text { 13:00h e 17:30h }\end{array}$ & \\
\hline $\begin{array}{l}2^{\circ} \text { semestre } \\
\text { letivo }\end{array}$ & $\begin{array}{l}\text { Entre } 1^{0} \text { de } \\
\text { agosto e } 15 \\
\text { de dezembro }\end{array}$ & $\begin{array}{l}\text { Ocupado entre 07:00h e } \\
\text { 11:30h, 13:00h e 17:30h } \\
\text { e 18:30h e 22:00h }\end{array}$ & \\
\hline
\end{tabular}

Fonte: Os autores.

\section{Resultados e discussão}

$\mathrm{Na}$ análise comparativa entre os modelos análogos às edificações estudadas e os modelos para teste de variáveis e modelos de referências listados na Tabela 2, verificou-se que, naqueles cujo uso principal é constituído de salas de aula (Central de Aulas 3 e Central de Aulas 6), a influência dos elementos de envoltória no consumo anual de eletricidade possui menor potencial de variação de consumo de eletricidade, em relação ao que é constatado na edificação de laboratórios (ver Figuras 6 a 21). Esse fato pode ser associado aos diferentes tipos de uso destas edificações e, consequentemente, às cargas energéticas dissipadas nos espaços internos das edificações estudadas, devido à maior densidade de ocupantes nas salas de aula (PEDRINI; WESTPHAL; LAMBERTS, 2002). Na Tabela 3 são apresentados os valores referentes ao consumo de energia elétrica anual nas edificações estudadas e os valores referentes ao consumo dos sistemas de iluminação, de condicionamento de ar e demais equipamentos existentes, conforme as características reais descritas na Tabela 1. Nas edificações de salas de aula, percebe-se que o consumo do sistema de condicionamento de ar prevaleceu, representando aproximadamente $80 \%$ do consumo de eletricidade, enquanto que na edificação de laboratórios, predominou o consumo de eletricidade anual dos equipamentos, que equivaleu a $49,70 \%$ do consumo anual da edificação, ante os $34,78 \%$ representado pelo sistema de condicionamento de ar.
Comparativamente aos três casos expostos na Tabela 1, os modelos para teste de variáveis e os modelos de referência parametrizados conforme o RTQ-C para avaliação da envoltória, apresentaram variações quanto ao consumo anual de eletricidade em relação aos respectivos casos base. Quanto ao consumo representado pelo sistema de iluminação e pelos equipamentos, todos os modelos apresentaram consumos de eletricidade idênticos aos respectivos casos base, já que neste estudo foram adotados valores constantes para estes parâmetros. Portanto, o sistema de condicionamento de ar foi o responsável por toda a variação de consumo anual de eletricidade, ocorrida em função das variáveis arquitetônicas testadas. Verificou-se também que a edificação de laboratórios foi mais suscetível a variações de consumo de energia elétrica, em função das características arquitetônicas que a constitui.

Quando analisados modelos com diferentes valores de absortância solar das superfícies de revestimento externo das edificações, verificou-se que há relação desta característica com o consumo anual de eletricidade. Nas Figuras 6 a 9 são demonstradas que a variação do consumo de eletricidade, de acordo com a absortância dos revestimentos das paredes externas ou cobertura, foi percentualmente maior nos modelos referentes à edificação de laboratórios, em relação ao caso real. A edificação Central de Aulas 3, que é uma edificação térrea, apresentou maior variação do consumo anual de eletricidade, conforme o valor do índice de absortância solar da cobertura (Figuras 6 e 7), enquanto que a Central de Aulas 6, que possui dois pavimentos, foi mais suscetível à absortância das paredes externas (Figuras $8 \mathrm{e}$ 9). Estes últimos exemplos demonstram que a combinação entre a geometria da edificação e a absortância térmica das superfícies, quando consideradas edificações de mesmo uso, são aspectos determinantes quanto ao nível de calor absorvido pela envoltória da edificação. Esse fato ocorre devido à distribuição das maiores áreas expostas à radiação solar e quanto ao índice de absorção de calor superficial a partir da insolação (CARLO; LAMBERTS, 2010a; GRÜNBERG; MEDEIROS; TAVARES, 2014; LAMBERTS; DUTRA; PEREIRA, 2014; SZOKOLAY, 2008).

Tabela 3 - Dados de consumo de energia elétrica simulados no programa EnergyPlus para as três edificações analisadas neste estudo, considerando as características reais (casos base)

\begin{tabular}{ccccccccc} 
Edificações & \multicolumn{2}{c}{ lluminação } & \multicolumn{2}{c}{ Equipamentos } & \multicolumn{2}{c}{$\begin{array}{c}\text { Condicionamento } \\
\text { de ar }\end{array}$} & \multicolumn{2}{c}{ Total } \\
& kWh/ano & \% & kWh/ano & \% & kWh/ano & \% & kWh/ano & kWh/ano/m \\
\hline Central de Aulas 3 & $35.196,35$ & 14,31 & $9.447,04$ & 3,84 & $201.361,75$ & 81,85 & $246.005,14$ & 239,41 \\
\hline Central de Aulas 6 & $49.201,41$ & 16,77 & $11.248,85$ & 3,83 & $232.970,79$ & 79,40 & $293.421,04$ & 221,74 \\
\hline Laboratório de Química, Física e Matemática & $49.201,41$ & 15,51 & $157.645,75$ & 49,70 & $110.327,66$ & 34,78 & $317.174,82$ & 251,28 \\
\hline
\end{tabular}


Figura 6 - Influência da absortância térmica dos elementos de cobertura no consumo de eletricidade anual nas três edificações: Central de Aulas 3 (CA3), Central de Aulas 6 (CA6) e Laboratório de Química, Física e Matemática (QFM)

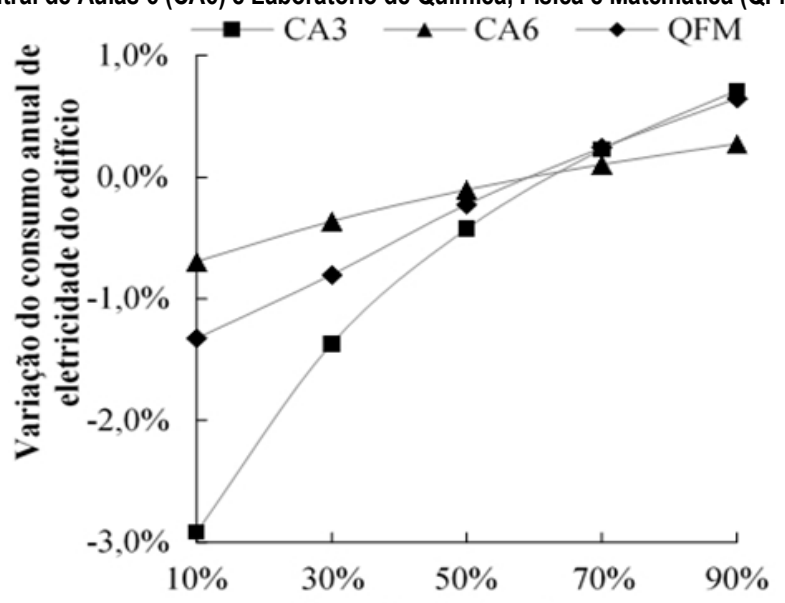

Fonte: Os autores.

Figura 7 - Influência da absortância térmica dos elementos de cobertura no consumo de eletricidade pelo sistema de condicionamento de ar nas três edificações investigadas: Central de Aulas 3 (CA3), Central de Aulas 6 (CA6) e Laboratório de Química, Física e Matemática (QFM)

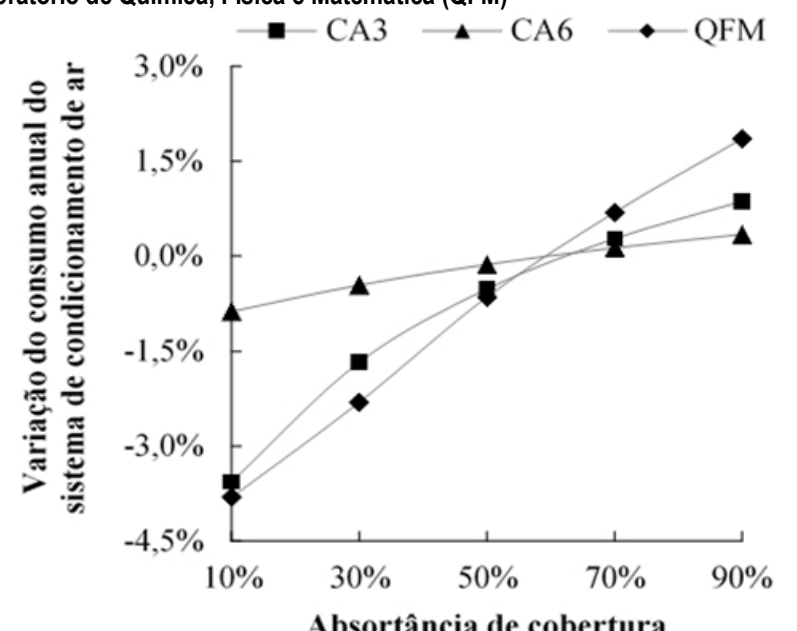

Fonte: Os autores.

Figura 8 - Influência da absortância térmica de paredes externas no consumo de eletricidade anual nas três edificações investigadas: Central de Aulas 3 (CA3), Central de Aulas 6 (CA6) e Laboratório de Química, Física e Matemática (QFM)

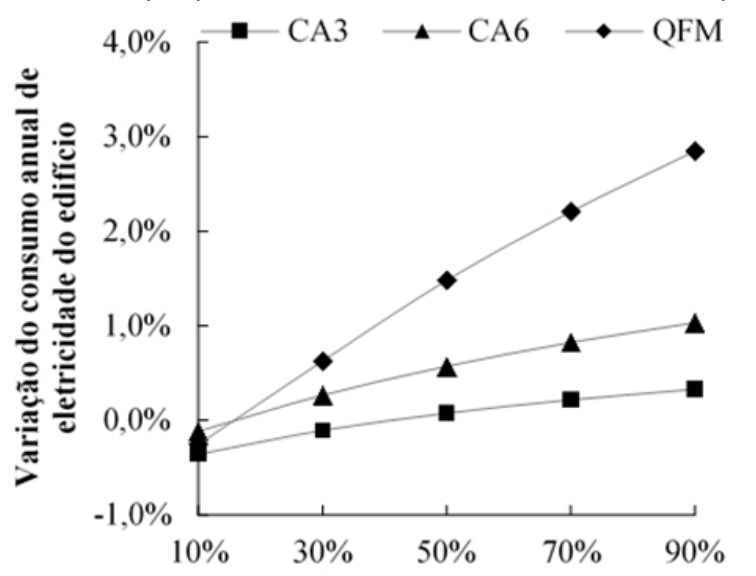

Absortância das paredes externas

Fonte: Os autores.
Figura 9 - Influência da absortância térmica de paredes externas no consumo de eletricidade pelo sistema de condicionamento de ar nas três edificações investigadas: Central de Aulas 3 (CA3), Central de Aulas 6 (CA6) e Laboratório de Química, Física e Matemática (QFM)

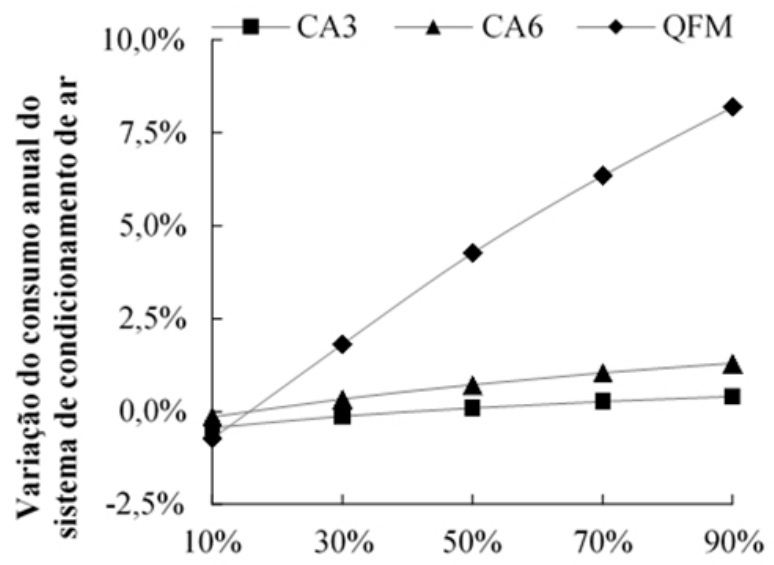

Absortância das paredes externas

Fonte: Os autores.

A partir da análise comparativa de modelos configurados com diferentes sistemas construtivos de cobertura e das paredes externas, demonstrou-se que há variação do consumo de energia elétrica anual em função das propriedades térmicas desses elementos arquitetônicos. Nas Figuras 10 e 11, demonstra-se que, quanto maior o valor da transmitância da cobertura, maior será o consumo de eletricidade. A transmitância térmica das paredes externas apresentou variações relevantes apenas no exemplo da edificação de laboratórios, com a redução de até $1,31 \%$ e, acréscimos de até $8,39 \%$ do consumo de eletricidade anual (Figuras 12 e 13). Nos casos das edificações de salas de aula, houve pouca variação do consumo anual de energia elétrica (menor que $0,7 \%$ ). Verificou-se também que a variação do consumo de energia elétrica total ou consumo pelo condicionamento de ar tendeu a ser menor nos casos em que a transmitância de cobertura é inferior a $2,0 \mathrm{~W} / \mathrm{m}^{2} . \mathrm{K}$ e nos casos em que a transmitância das paredes externas é inferior a 3,0 $\mathrm{W} / \mathrm{m}^{2} . \mathrm{K}$.

O percentual de aberturas nas fachadas (PAF) está associado diretamente ao aumento das cargas térmicas nas edificações, pois os elementos translúcidos permitem que haja incidência direta da radiação solar para o interior da edificação. Nos casos estudados, os modelos demonstraram que, quanto maior o percentual de áreas translúcidas na fachada, maior será o consumo de energia elétrica predial, devido ao consumo de eletricidade para condicionamento de ar (Figuras 14 e 15). A variação do consumo anual de energia elétrica foi observada de modo mais relevante na edificação de laboratórios, com redução de 2,68\% do consumo de eletricidade anual no modelo com PAF de $10,0 \%$, e acréscimos de até $17,19 \%$ no modelo de PAF igual a 70,0\%. Nos casos das edificações de salas de aula, houve menor variação do consumo anual 
de energia elétrica em comparação aos casos base, com acréscimos menores que $3,80 \%$ e reduções de até $1,0 \%$ no que se refere ao consumo anual de eletricidade. Verificouse também, que a variação do consumo de energia elétrica total e consumo pelo condicionamento de ar nos casos estudados cresce de modo linear à medida que a proporção de áreas envidraçadas nas fachadas é ampliada.

Figura 10 - Influência da transmitância térmica dos elementos de cobertura no consumo de eletricidade anual nas três edificações investigadas: Central de Aulas 3 (CA3), Central de Aulas 6 (CA6) e Laboratório de Química, Física e Matemática (QFM)

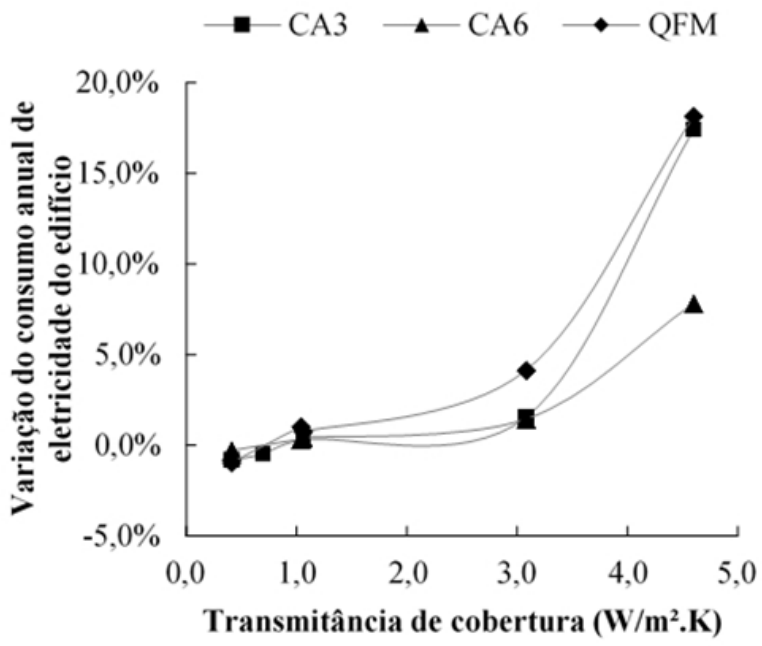

Fonte: Os autores

Figura 11 - Influência da transmitância térmica dos elementos de cobertura no consumo de eletricidade pelo sistema de condicionamento de ar nas três edificações investigadas: Central de Aulas 3 (CA3), Central de Aulas 6 (CA6) e Laboratório de Química, Física e Matemática (QFM)

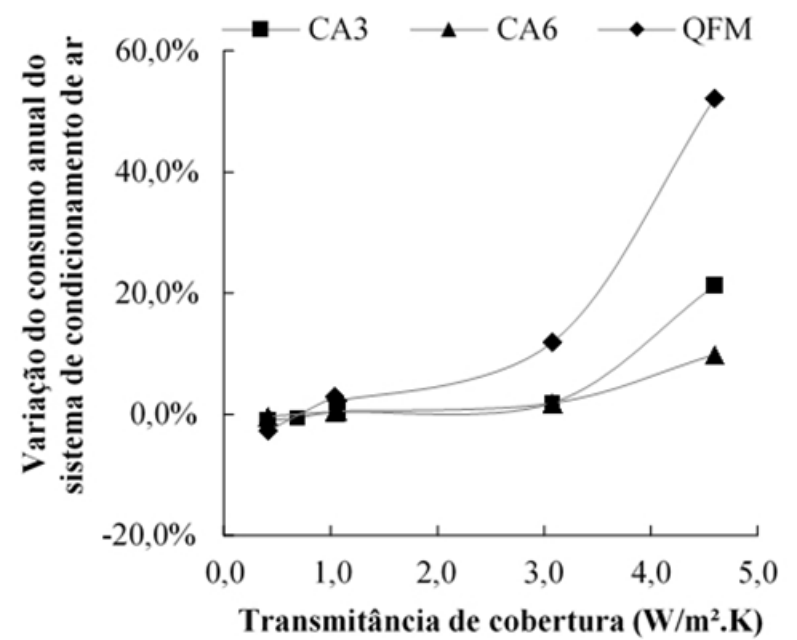

Fonte: Os autores.
Figura 12 - Influência da transmitância térmica de paredes externas no consumo de eletricidade anual nas três edificações investigadas: Central de Aulas 3 (CA3), Central de Aulas 6 (CA6) e Laboratório de Química, Física e Matemática (QFM)

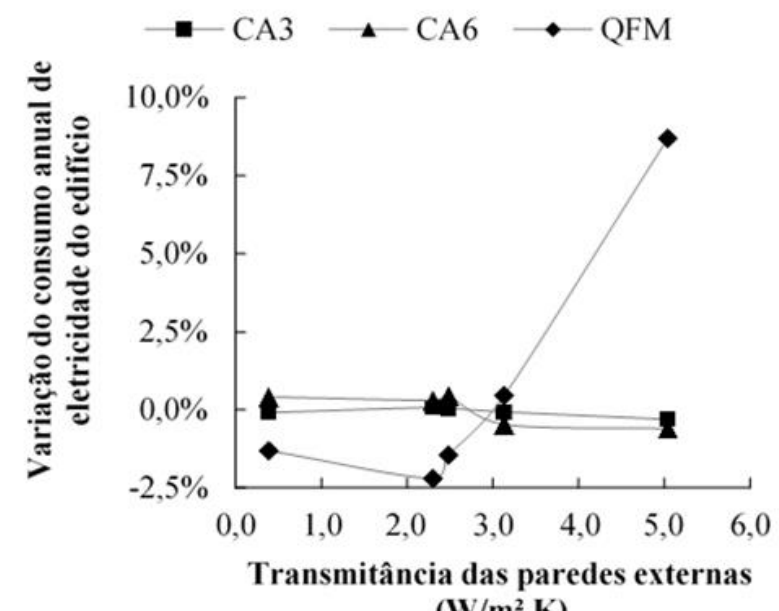

$\left(\mathbf{W} / \mathbf{m}^{2} . \mathbf{K}\right)$

Fonte: Os autores.

Figura 13 - Influência da transmitância térmica de paredes externas no consumo de eletricidade pelo sistema de condicionamento de ar nas três edificações investigadas: Central de Aulas 3 (CA3), Central de Aulas 6 (CA6) e Laboratório de Química, Física e Matemática (QFM)

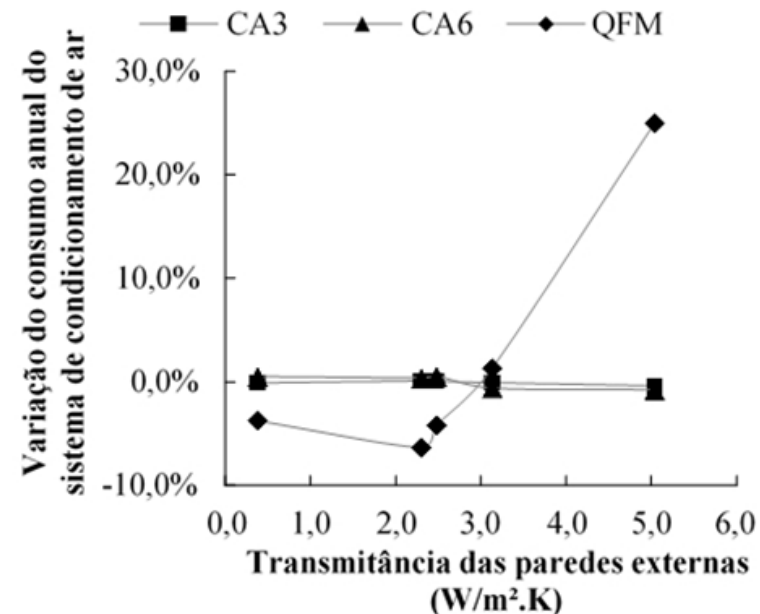

Fonte: Os autores

Figura 14 - Influência do percentual de aberturas das fachadas no consumo de eletricidade anual nas três edificações: Central de Aulas 3 (CA3), Central de Aulas 6 (CA6) e Laboratório de Química, Física e Matemática (QFM)

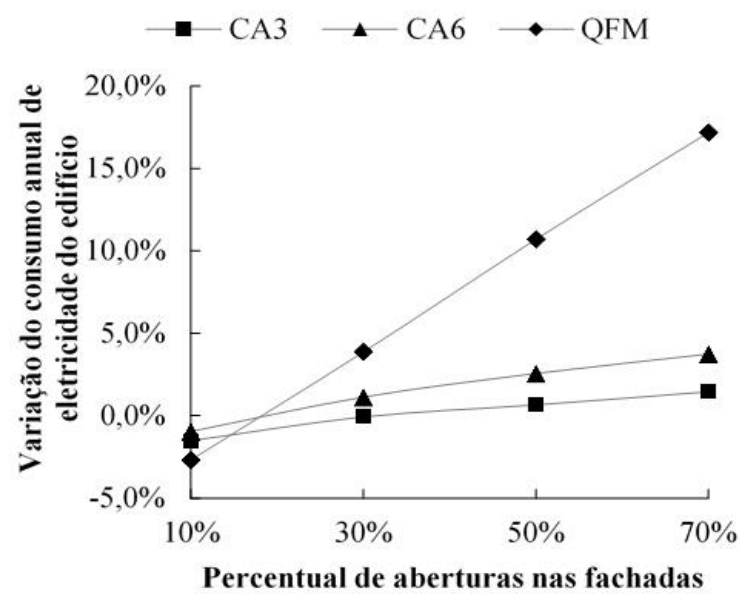

Fonte: Os autores 
Figura 15 - Influência do percentual de aberturas das fachadas no consumo de eletricidade pelo sistema de condicionamento de ar nas três edificações investigadas: Central de Aulas 3 (CA3), Central de Aulas 6 (CA6) e Laboratório de Química, Física e Matemática (QFM)

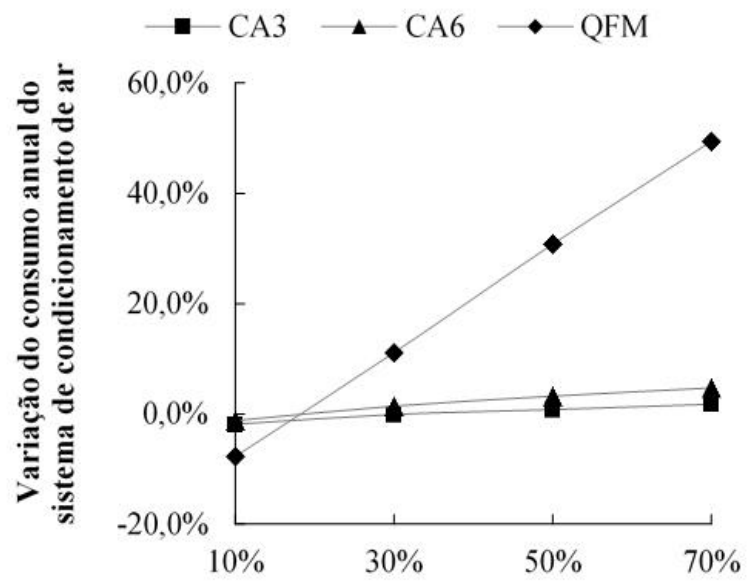

Fonte: Os autores.

Percentual de aberturas nas fachadas

No que se refere ao sombreamento das áreas envidraçadas das edificações estudadas, verificou-se que, quando são considerados maiores ângulos verticais de sombreamento, obtém-se maior redução do consumo anual de eletricidade. Nas Figuras 16 e 17, demonstra-se que a redução do consumo de eletricidade ocorreu em conformidade com o valor do ângulo de sombreamento vertical nos estudos de caso realizados. Deve-se destacar novamente o caso da edificação QFM (Laboratórios de Química, Física e Matemática), para o qual se observou a redução de até $7,81 \%$ no consumo anual de eletricidade do sistema de condicionamento de ar, com a utilização de elementos arquitetônicos com $60^{\circ}$ de ângulo de sombreamento vertical.

Figura 16 - Influência do ângulo de sombreamento vertical no consumo de eletricidade anual nas três edificações investigadas: Central de Aulas 3 (CA3), Central de Aulas 6 (CA6) e Laboratório de Química, Física e Matemática (QFM)

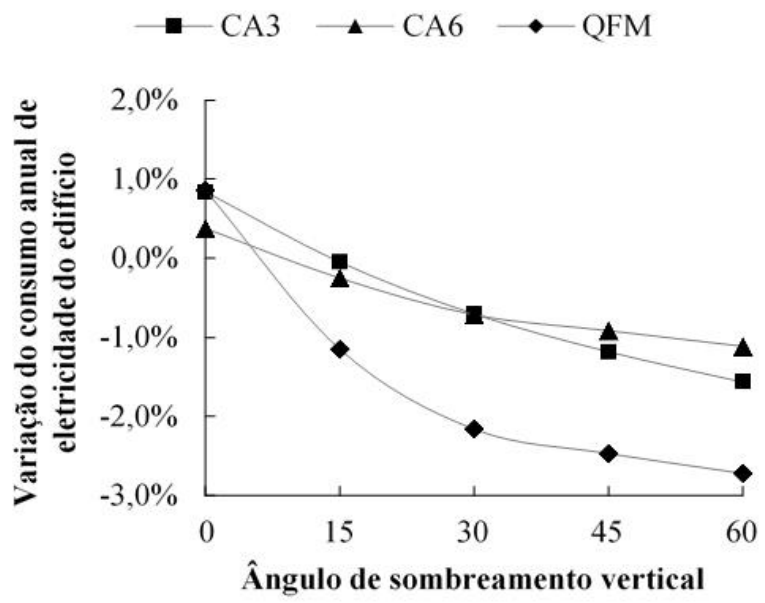

Fonte: Os autores.

Figura 17 - Influência do ângulo de sombreamento vertical no consumo de eletricidade pelo sistema de condicionamento de ar nas três edificações investigadas: Central de Aulas 3 (CA3), Central de Aulas 6 (CA6) e Laboratório de Química, Física e Matemática (QFM)

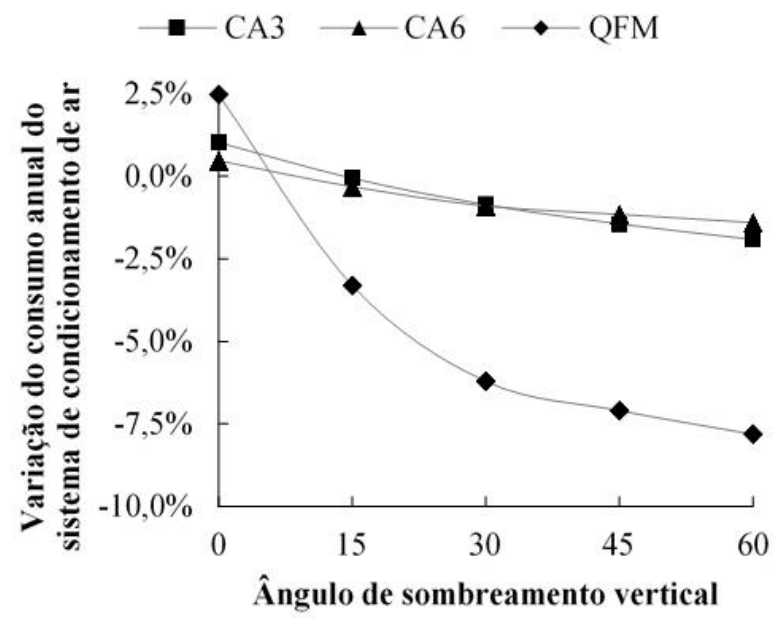

Fonte: Os autores.

A orientação cardeal está relacionada com a implantação da edificação e a distribuição geométrica desta em relação ao norte geográfico e, consequentemente, à distribuição da incidência de radiação solar na edificação ao longo do ano (AL ANZI; SEO; KRARTI, 2009; LAMBERTS et al., 2014; SZOKOLAY, 2008). Desse modo, o estudo realizado demonstrou que existem variações de consumo anual de energia elétrica, de acordo com a disposição das fachadas mais extensas da edificação em relação ao terreno. Nas Figuras 18 e 19 demonstra-se que o alinhamento ao norte ou ao sul das fachadas mais extensas propicia a redução do consumo anual de eletricidade, comparativamente às demais orientações. Verifica-se também que, em orientações cujo alinhamento das maiores fachadas é direcionado a leste ou a oeste, há acréscimos no consumo de energia elétrica, e que o consumo de eletricidade é intermediário quando a maior dimensão da edificação está direcionada aos pontos colaterais: nordeste, noroeste, sudeste e sudoeste. O comportamento da edificação QFM (Laboratórios de Química, Física e Matemática), demonstra que esta, apesar de ter maior densidade de equipamentos e por possuir menor densidade de usuários por área, apresenta menor densidade de carga térmica interna, sendo mais suscetível às condições às quais a envoltória da edificação está submetida. 
Figura 18 - Influência da orientação cardeal de implantação do edifício no consumo de eletricidade anual em três edificações investigadas: Central de Aulas 3 (CA3), Central de Aulas 6 (CA6) e Laboratório de Química, Física e Matemática (QFM)

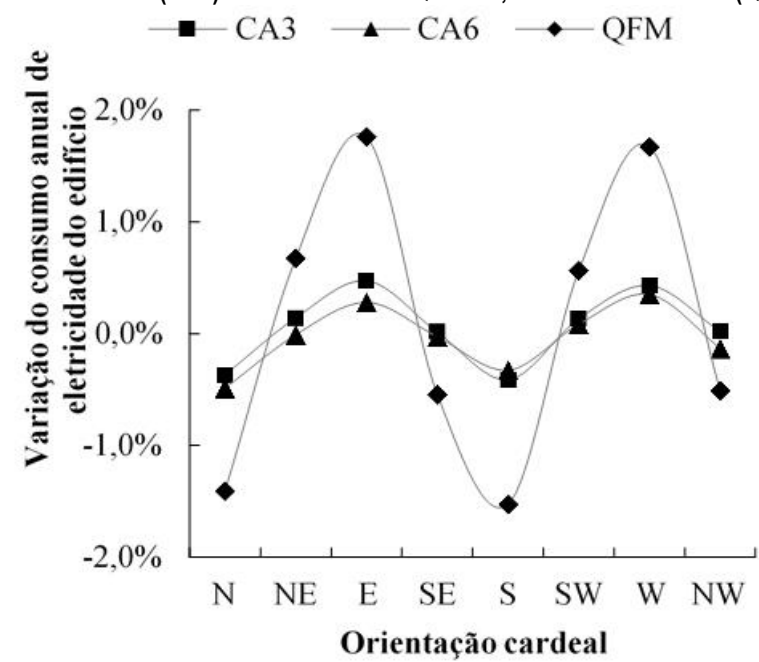

Fonte: Os autores.

Figura 19 - Influência da orientação cardeal de implantação da edificação no consumo de eletricidade pelo sistema de condicionamento de ar nas três edificações investigadas: Central de Aulas 3 (CA3), Central de Aulas 6 (CA6) e Laboratório de Química, Física e Matemática (QFM)

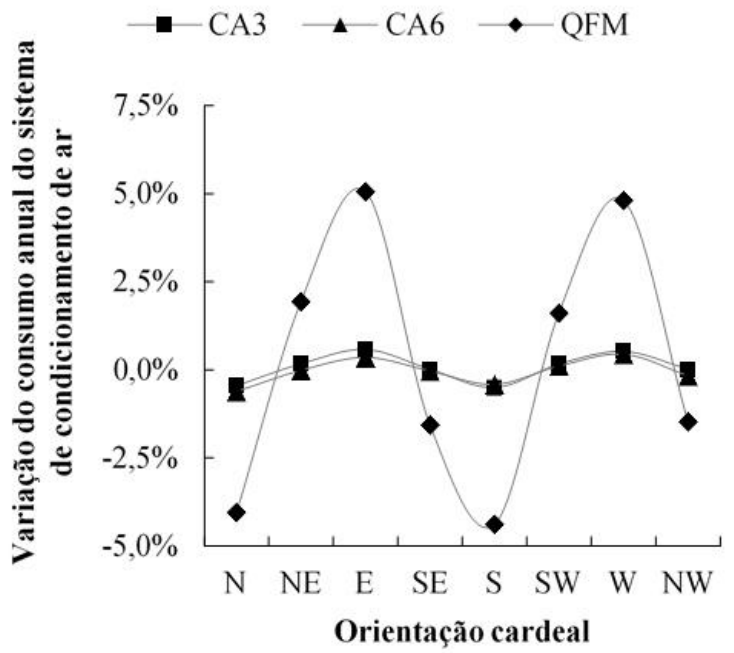

Fonte: Os autores.

Nas Figuras 20 e 21 são apresentados os desempenhos referentes aos modelos parametrizados conforme os quatro benchmarks referentes aos níveis de classificação previstos no RTQ-C em relação às respectivas edificações estudadas. Em todas as edificações estudadas, verificou-se que os sistemas de envoltória apresentaram desempenho superior aos benchmarks definidos pelo RTQ-C (INMETRO, 2010), e que, portanto, os três seriam qualificados como Nível A. Esse desempenho se justifica porque as edificações, objetos deste estudo, são constituídas por revestimentos e sistemas construtivos Figuras 6 a 9) com absortância e transmitância térmica majoritariamente inferiores às exigências do RTQ-C. Portanto, esses revestimentos e sistemas construtivos contribuem para a redução dos efeitos do clima tropical semiárido nos ganhos térmicos da construção. Quanto às características geométricas dos elementos de envoltória, as edificações estudadas possuem baixo percentual de aberturas nas fachadas (entre 18 e $31 \%$ ) e possuem elementos de sombreamento como as marquises de cobertura, enquanto que os modelos de referência desconsideram estes elementos.

Figura 20 - Consumo de eletricidade anual dos modelos de referência conforme a classificação de eficiência energética em três edificações investigadas na Universidade Federal Rural do Semi-Árido - UFERSA, Mossoró, Rio Grande do Norte, Brasil: Central de Aulas 3 (CA3), Central de Aulas 6 (CA6) e Laboratório de Química, Física e Matemática (QFM)

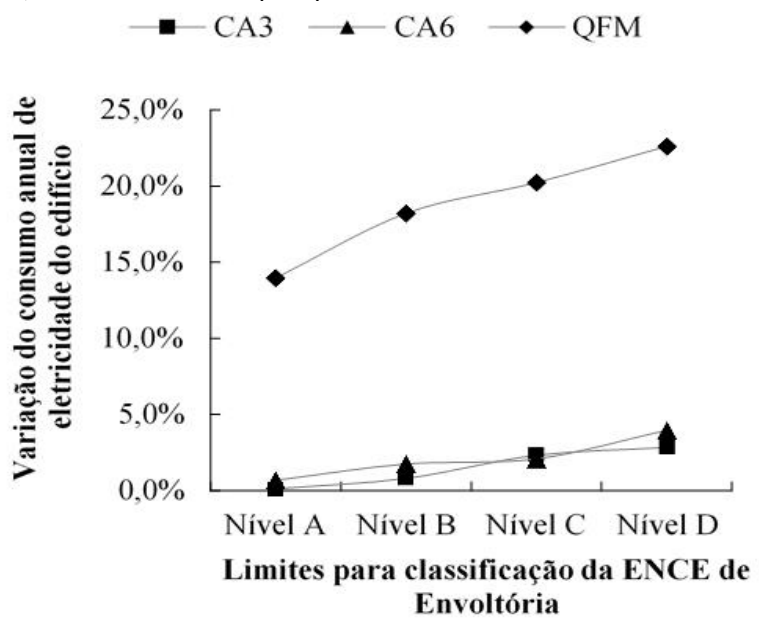

Fonte: Os autores

Figura 21 - Consumo de eletricidade pelo sistema de condicionamento de ar dos modelos de referência conforme a classificação de eficiência energética em três edificações investigadas na Universidade Federal Rural do Semi-Árido - UFERSA, Mossoró, Rio Grande do Norte, Brasil: Central de Aulas 3 (CA3), Central de Aulas 6 (CA6) e Laboratório de Química, Física e Matemática (QFM)

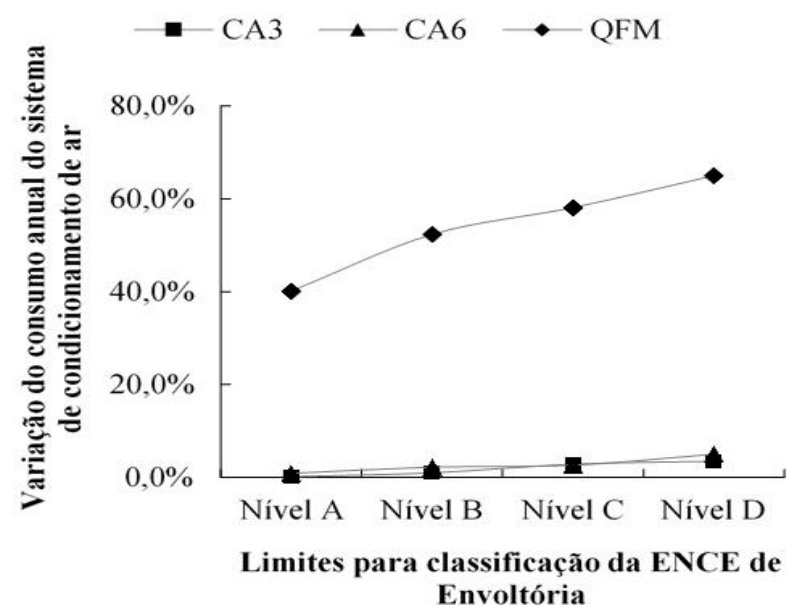

Fonte: Os autores.

\section{Considerações Finais}

As simulações demonstraram que os aspectos arquitetônicos e construtivos da envoltória analisados nos estudos de caso influenciaram o consumo de energia elétrica de edificações climatizadas situadas no clima tropical semiárido brasileiro. Os modelos para teste de variáveis e os modelos de referência, propostos pelo INMETRO (2010) para avaliação da envoltória quanto ao nível de eficiência energética, apresentaram variações 
quanto ao consumo anual de eletricidade em relação às três edificações estudadas. Estas variações estão diretamente relacionadas às características arquitetônicas de envoltória da edificação e à influência destes elementos no ganho térmico da construção, consequentemente, nos efeitos deste ganho no consumo de eletricidade pelos sistemas de condicionamento artificial de ar.

A partir da análise das três edificações abrangidas pelo estudo, verificou-se que existem aspectos que contribuem para a otimização do desempenho da envoltória no clima tropical semiárido e, consequentemente, para a redução do consumo de eletricidade pelo sistema de condicionamento artificial de ar. As seguintes características contribuíram para minimizar os efeitos da radiação solar no aquecimento das edificações: (i) os revestimentos das edificações estudadas, compostos majoritariamente de cores claras e refletivas, (ii) o baixo percentual de áreas envidraçadas nas fachadas e (iii) a existência de marquises que sombreiam as paredes externas e as aberturas envidraçadas das fachadas nos períodos mais quentes dos dias, ao longo do ano. Estes aspectos positivos são suficientes para compensação das características que não atendem aos parâmetros recomendados pelo INMETRO, ou que demonstraram desempenho mediano, como o que foi apresentado pela excessiva absorção de calor pela cobertura da edificação, devido à absortância térmica de $60 \%$. Esta contrapartida das características e dos elementos construtivos que contribuem para a redução do consumo de energia elétrica predial foi suficiente para que a envoltória das três edificações estudadas obtivesse desempenho melhor do que os benchmarks propostos pelo INMETRO na avaliação de eficiência energética das edificações (INMETRO, 2010).

Com base no estudo realizado e objetivando a redução do consumo de eletricidade em edificações institucionais climatizadas no clima tropical semiárido, bem como a obtenção da classificação Nível A da ENCE de Envoltória, recomenda-se que os projetos arquitetônicos destas atentem ou priorizem os seguintes aspectos:

a) utilizar sistemas construtivos de cobertura, cuja transmitância térmica seja inferior a $1,0 \mathrm{~W} / \mathrm{m}^{2} . \mathrm{K}$;

b) utilizar sistemas construtivos em paredes externas, cuja transmitância térmica seja inferior a $3,0 \mathrm{~W} / \mathrm{m}^{2} . \mathrm{K}$;

c) dar preferência à utilização de cores claras nos revestimentos de fachadas e de elementos de cobertura, em geral, com baixa absortância térmica (inferior a 50\%);

d) adequar as áreas envidraçadas para que estejam protegidas da radiação solar direta, seja pela utilização de elementos de sombreamento ou pela redução da área translúcida, desde que não se prejudique a iluminação natural dos ambientes;

e) planejar ruas, lotes e quarteirões de modo a permitir que, na implantação das edificações, as fachadas com maiores dimensões estejam orientadas para o norte e para o sul.

\section{Agradecimentos}

Os autores agradecem à Universidade Federal Rural do Semi-Árido - UFERSA pelo fornecimento das informações referentes aos projetos das edificações estudadas e ao Laboratório de Eficiência Energética em Edificações - LabEEE da Universidade Federal de Santa Catarina-UFSC pela disponibilização do arquivo climático padronizado, contendo as informações climatológicas do município de Mossoró, RN.

\section{Referências}

AHMAD, Q.; SZOKOLAY, S. Validation of thermal design tools. International Energy Journal, v. 16, n. 2, 2017.

AL ANZI, A.; SEO, D.; KRARTI, M. Impact of building shape on thermal performance of office buildings in Kuwait. Energy Conversion and Management, v. 50, p. 822-828, 2009. DOI:https://doi.org/10.1016/j.enconman.2008.09.033.

ALVARES, C. A. et al. Köppen's climate classification map for Brazil. Meteorologische Zeitschrift, v. 22, n. 6, p. 711-728, 2013. DOI: https://doi.org/10.1127/0941-2948/2013/0507.

ARENT, D. et al. Implications of high renewable electricity penetration in the US for water use, greenhouse gas emissions, landuse, and materials supply. Applied Energy, v. 123, p. 368-377, 2014. DOI:https://doi.org/10.1016/j.apenergy.2013.12.022.

ABNT - ASSOCIAÇÃO BRASILEIRA DE NORMAS TÉCNICAS. NBR 15220-2: Desempenho térmico de edificações. Parte 2: Métodos de cálculo da transmitância térmica, da capacidade térmica, do atraso térmico e do fator de calor solar de elementos e componentes de edificações. Rio de Janeiro: ABNT, 2005. 
BALSLEV, Y. J.; POTCHTER, O.; MATZARAKIS, A. Climatic and thermal comfort analysis of the Tel-Aviv Geddes Plan: A historical perspective. Building and Environment, v. 93, p. 302-318, 2015. DOI:https://doi.org/10.1016/j.buildenv.2015.07.005.

CARLO, J. C.; LAMBERTS, R. Development of envelope efficiency labels for commercial buildings: Effect of different variables on electricity consumption. Energy and Buildings, n. 40, p. 2002-2008, 2008. DOI:https://doi.org/10.1016/j.enbuild.2008.05.002.

CARLO, J. C.; LAMBERTS, R. Parâmetros e métodos adotados no regulamento de etiquetagem da eficiência energética de edifícios - parte 1: método prescritivo. Ambiente Construído, v. 10, n. 2, p. 7-26, abr.jun. 2010 a.

DOI:http://doi.org/10.1590/S1678-86212010000200001.

CARLO, J. C.; LAMBERTS, R. Parâmetros e métodos adotados no regulamento de etiquetagem da eficiência energética de edifícios - parte 2: método de simulação. Ambiente Construído, v. 10, n. 2, p. 27-40, abr./jun. $2010 \mathrm{~b}$.

DOI:http://doi.org/10.1590/S1678-86212010000200002.

CORGNATI, S. P.; KINDINIS, A. Thermal mass activation by hollow core slab coupled with night ventilation to reduce summer cooling loads. Building and Environment, v. 42, n. 9, p. 3285-3297, 2007. DOI:https://doi.org/10.1016/j.buildenv.2006.08.018.

DOE - U.S. DEPARTMENT OF ENERGY. EnergyPlus. Version 8.2.0. [S.1.]:, 2015. Disponível em: https://energyplus.net. Acesso em: 24 maio 2015

FUMO, N.; MAGO, P.; LUCK, R. Methodology to estimate building energy consumption using EnergyPlus benchmark models. Energy and Buildings, v. 42, p. 2331-2337, 2010. DOI:https://doi.org/10.1016/j.enbuild.2010.07.027.

GRÜNBERG, P. R. M.; MEDEIROS, M. H. F. de; TAVARES, S. F. Environmental certification for habitations: comparison between LEED for Homes, Aqua process and "Selo Casa Azul". Ambiente \& Sociedade, v. 17, n. 2, p. 209-226, 2014. DOI:http://doi.org/10.1590/S1414-753X2014000200013.

INMETRO - INSTITUTO NACIONAL DE METROLOGIA, NORMALIZAÇÃO E QUALIDADE INDUSTRIAL. Portaria n. ${ }^{\circ}$ 372, de 17 de setembro de 2010. Regulamento Técnico da Qualidade para o Nível de Eficiência Energética de Edifícios Comerciais, de Serviço e Públicos. Rio de Janeiro: Instituto Nacional de Metrologia, Normalização e Qualidade Industrial, 2010.

INMETRO - INSTITUTO NACIONAL DE METROLOGIA, NORMALIZAÇÃO E QUALIDADE INDUSTRIAL. Portaria n. ${ }^{\circ}$ 50, de 01 de fevereiro de 2013. Requisitos da Avaliação da Conformidade para Eficiência Energética de Edificações. Rio de Janeiro: Instituto Nacional de Metrologia, Normalização e Qualidade Industrial, 2013.

JI, L. et al. Greenhouse gas emission factors of purchased electricity from interconnected grids. Applied Energy, v. 184, p. 751758, 2016. DOI:https://doi.org/10.1016/j.apenergy.2015.10.065.

KATS, G. Tornando nosso ambiente construído mais sustentável. Custos, benefícios e estratégias. São Paulo: Island Press, 2014. ISBN 978-1-59726-668-0.

LAMBERTS, R.; DUTRA, L.; PEREIRA, F. O. R. Eficiência energética na arquitetura. $3^{\text {a }}$ Ed. São Paulo: Eletrobrás/Procel, 2014.

MARTINEZ, M. F. et al. Redução de consumo de energia elétrica através de conceitos green building. Eletrônica de Potência, v. 14, n. 2, p. 141-148, maio 2009. DOI: http://doi.org/10.18618/REP.2009.2.141148.

MASCARÓ, J. L. O Custo das decisões arquitetônicas. 3ª ed. Porto Alegre: JLM, 2004.

NEVES, Letícia de Oliveira; MACHADO, Rodrigo Dias; CAVALCANTE, Rodrigo. Desempenho térmico do edifício da FAU Maranhão em dois momentos históricos. PARC Pesquisa em Arquitetura e Construção, Campinas, SP, v. 7, n. 4, p. 211-224, dez. 2016. ISSN 1980-6809. DOI:https://doi.org/10.20396/parc.v7i4.8646323.

OLIVEIRA, E. A. S. de et al. Human thermal comfort and architectural volume. Acta Scientiarum - Tecnology, v. 38, n. 2, p. 129135, 2016. DOI:https://doi.org/10.4025/actascitechnol.v38i2.28308.

PEDRINI, A.; WESTPHAL, F. S.; LAMBERTS, R. A methodology for building energy modelling and calibration in warm climates. Building and Environment, v. 37, n. 8, p. 903-912, 2002. DOI:https://doi.org/10.1016/S0360-1323(02)00051-3. 
PÉREZ-LOMBARD, L. et al. A review of benchmarking, rating and labelling concepts within the framework of building energy certification schemes. Energy and Buildings, v. 41, p. 272-278, 2009. DOI:https://doi.org/10.1016/j.enbuild.2008.10.004.

REY, F. J.; VELASCO, E.; VARELA, F. Building Energy Analysis (BEA): A methodology to assess building energy labelling. Energy and Buildings, n. 39, p. 709-716, 2007. DOI:https://doi.org/10.1016/j.enbuild.2006.07.009.

RORIZ, M. Laboratório de eficiência energética em edificações. Arquivos climáticos em formato EPW. Florianópolis: Laboratório de Eficiência Energética em Edificações. 2012. Disponível em: http://www.labeee.ufsc.br/downloads/arquivosclimaticos/formato-epw . Acesso em: 29 jun. 2015.

STANKEVICIUS, V.; KARBAUSKAITE, J.; MONSTVILAS, E. The development of reference values for energy certification of buildings in Lithuania. Energy and Buildings, n. 39, p. 284-288, 2007. DOI:https://doi.org/10.1016/j.enbuild.2006.05.008.

SZOKOLAY, S. V. Introduction to architectural science: the basis of sustainable design. $2^{\mathrm{a}}$ ed. Routledge, 2008. ISBN 1317918592.

\section{${ }^{1}$ Paolo Américo de Oliveira}

Arquiteto e Urbanista. Mestre em Ambiente, Tecnologia e Sociedade. Arquiteto e Urbanista na Universidade Federal Rural do Semi-Árido. Endereço postal: Avenida Francisco Mota, 572, Mossoró, RN, Brasil, CEP: 59.265-900.

\section{${ }^{2}$ Diana Gonçalves Lunardi}

Bióloga. Doutora em Psicobiologia. Professora Doutora na Universidade Federal Rural do Semi-Árido. Endereço postal: Avenida Francisco Mota, 572, Mossoró, RN, Brasil, CEP: 59.265-900. 